\title{
Computational Fluid Dynamic Simulation (CFD) and Experimental Study on Wing-external Store Aerodynamic Interference of a Subsonic Fighter Aircraft
}

\begin{abstract}
Tholudin Mat Lazim, Shabudin Mat, Huong Yu Saint
The main objective of the present work is to study the effect of an external store on a subsonic fighter aircraft. Generally most modern fighter aircrafts are designed with an external store installation. In this study, a subsonic fighter aircraft model has been manufactured using a computer numerical control machine for the purpose of studying the effect of the aerodynamic interference of the external store on the flow around the aircraft wing. A computational fluid dynamic (CFD) simulation was also carried out on the same configuration. Both the CFD and the wind tunnel testing were carried out at a Reynolds number $1.86 \times 10^{5}$ to ensure that the aerodynamic characteristic can certify that the aircraft will not be face any difficulties in its stability and controllability. Both the experiments and the simulation were carried out at the same Reynolds number in order to verify each other. In the CFD simulation, a commercial CFD code was used to simulate the interference and aerodynamic characteristics of the model. Subsequently, the model together with an external store was tested in a low speed wind tunnel with a test section sized $0.45 \mathrm{~m} \times 0.45 \mathrm{~m}$. Measured and computed results for the two-dimensional pressure distribution were satisfactorily comparable. There is only a $19 \%$ deviation between pressure distribution measured in wind tunnel testing and the result predicted by the CFD. The result shows that the effect of the external storage is only significant on the lower surface of the wing and almost negligible on the upper surface of the wing. Aerodynamic interference due to the external store was most evident on the lower surface of the wing and almost negligible on the upper surface at a low angle of attack. In addition, the area of influence on the wing surface by the store interference increased as the airspeed increased.
\end{abstract}

Keywords: computational fluid dynamic (CFD), wind tunnel testing, CFD validation, aerodynamic interference.

\section{Introduction}

Fighter aircraft are mostly designed to carry stores such as a launcher or an external tank under the wing. When these stores are installed, the flow on its surrounding components such as the control surfaces can be considerably changed. This may introduce several aerodynamic interference characteristics such as changes in aerodynamic force, increase in turbulence and possibly flow separation. These phenomena may cause an adverse effect on other aircraft components such as the horizontal tail and vertical stabilizer, and consequently may affect the controllability and stability of the aircraft. Research on external store installation is complex and extensive. It covers several research areas such as aerodynamics, structure, flutter, physical integration, trajectory prediction, aircraft performance, stability analysis and several multiple engineering disciplines. However, the focus of this work was to study the aerodynamic interference particularly on the change in aerodynamic characteristics. The aerodynamic characteristics are a prerequisite for the other analysis, since the aerodynamic data are required for a subsequent aircraft structural analysis, stability analysis, performance analysis and store trajectory analysis. Investigations of the aerodynamic characteristics in the external store clearance program usually involve a complex flow field study with multi component interferences. Flow of such a nature is usually investigated through wind tunnel testing and empirical methods.
The main objective in this study was to identify the interference effect of a subsonic fighter aircraft that is currently used by Royal Malaysian Air force with the presence of an external store installation. A generic model of one of the subsonic fighter aircraft used by Royal Malaysian Air Force was chosen for the study. Wind tunnel testing and computational fluid dynamics (CFD) simulation were conducted to investigate these interference effects. A low speed wind tunnel with a working section of $0.45 \mathrm{~m} \times 0.45 \mathrm{~m}$ was used to conduct the experiments and commercial CFD software was used for the simulation. Other milestones in this study include the verification and validation process and the suitability of applying a commercial CFD code for predicting the wing and external store aerodynamic interference effects.

\section{Simulation and experimental works}

The methodology adopted to conduct the study consists of several steps. The first and foremost was to obtain the digitized wing section geometry. The digitization process was done using Photomodeller software. The next step was to construct a scale model of the wing based on the digitized wing geometry using Numerical Control Machine (CNC). Then several series of experiments were carried out upon the scale model in the wind tunnel at a low speed of approximately $22.8 \mathrm{~m} / \mathrm{s}$. The digitized wing 

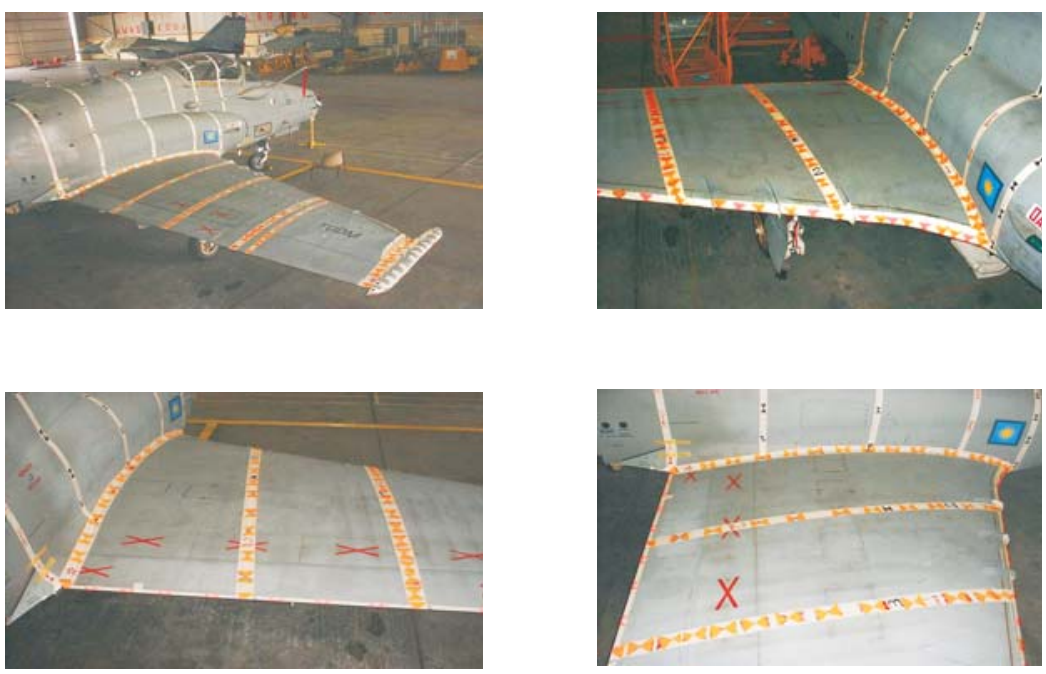

Fig. 1: Photographs of the marked wing surface at the various projection

geometry was also used in the CFD simulation. Gambit preprocessor software was used to produce the necessary mesh. The setup was then simulated using Fluent 5 CFD software and the CFD simulation was carried out with various physical models, numerical algorithms, a discretization method and boundary conditions. In the final step, the study was wrapped up by comparing the computed and measured results in a further investigation of the nature of the interference effect of a wing and external store configuration.

\section{Aircraft wing external geometry digitization}

Digitization of the wing geometry was vital in order to obtain an adequate aircraft model geometry representing the real aircraft Photomodeler 3.0 software was used to capture and digitize the aircraft wing external geometry. The software captured the image of 84 photographs taken at various angles of the aircraft wing. These photos were taken using a digital camera. A number of points were marked on the aircraft wing and the adjacent fuselage part using masking tape, as shown in Fig. 1. The size of the markers was designed to ensure clear and sharp visibility in photographs taken from a certain distance. This was

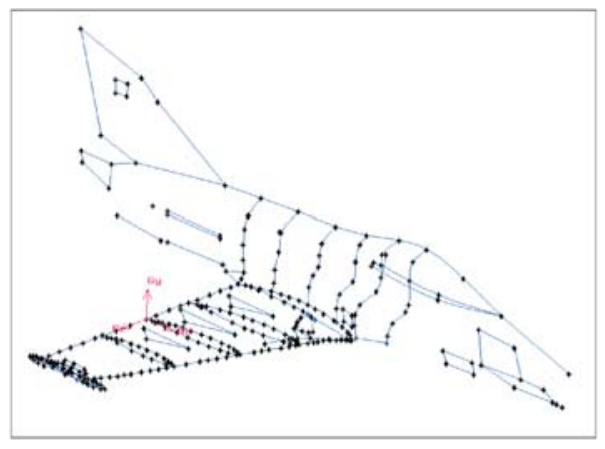

Fig. 2: Aircraft geometry produced by Photomodeller determined using the relationship between the number of pixels and the distance from the camera. The placement and location of the markers were determined based on the profile of the wing. The high curvature area was placed with denser markers. This figure also shows part of the total of 84 photographs used to generate the wing profile and some part of the fuselage.

The output from the digitization process was a set of coordinates conforming to the wing geometry, as shown in Fig. 2. Most of the coordinates were on the wing surface and wingtip pylon. Unfortunately, the wing geometry image was not of high quality in terms of accuracy and perfection. Therefore, CAD software was used to smooth the image. After minor adjustments were made, the image became as in Fig. 3.

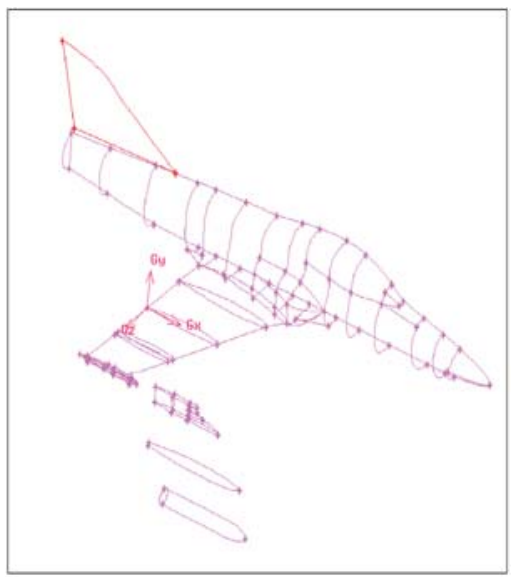

Fig. 3: Digitized wing geometry smoothed with the use of CAD

\section{Wind Tunnel Testing}

A wing model is required for wind tunnel testing. Therefore, a $20 \%$ scale wing model of a fighter aircraft was fabricated with the use of a CNC machine. The model was made from a single solid piece of aluminum-alloy with nine conduits each on the upper and lower surface. 


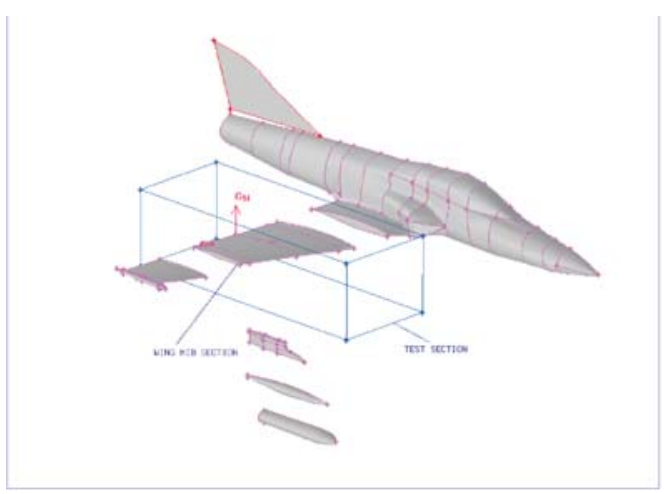

Fig. 4: Semi span model of a generic fighter aircraft

Fig. 4 shows the semi-span model of a generic fighter aircraft taken from the digitized geometry produced by Photomodeller.

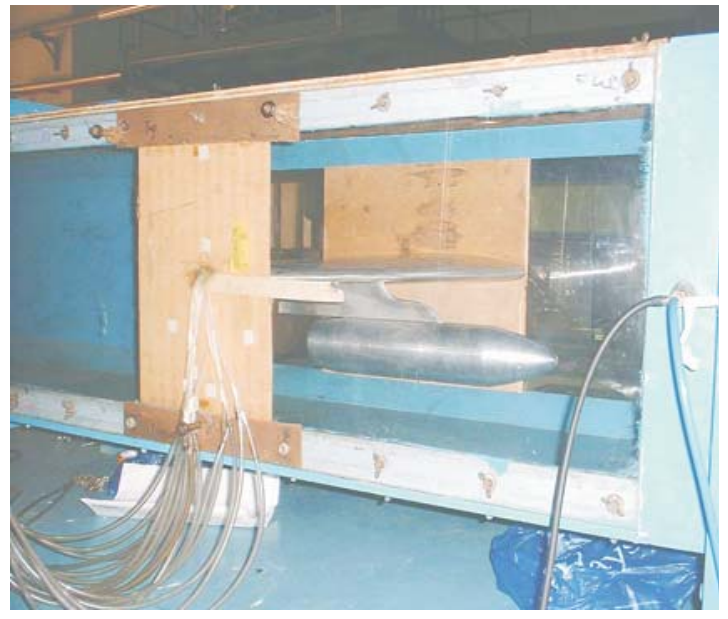

Fig. 5: Model installation inside the wind tunnel

The figure indicates three main parts of the wing: the root section, the mid section and the tip section. Since the external store was installed on the mid section, it was decided to fabri- cate only this section. Furthermore, it was not feasible to test the full set of the wing model, due to the limitation of the size of the wind tunnel test section. The model has three main stations for pressure measurement study located at the chord are parallel to each other and placed at with equal distances. Every station was equipped with static pressure-taping points on the upper and lower surface, respectively. Besides fabricating the mid wing model, a $1 / 5$ scale model of a launcher and a pylon as the external stores were also fabricated. These external stores were designed in such a way that they can be easily secured and removed from the wing section. Fig. 5 shows the complete assembly of this aircraft wing together with the external stores inside the test section. The test was conducted using two different configurations of the wing model. The first configuration was without the external store, while, the second configuration was with the external store installed. Both configurations were tested at zero angle of attack at two different speeds: $22 \mathrm{~m} / \mathrm{s}$ and $27 \mathrm{~m} / \mathrm{s}$. In this study, the wing model was tested in an open suction type low speed wind tunnel with a working section of $0.45 \mathrm{~m} \times 0.45 \mathrm{~m}$. Pressure measurement was carried out using a multi-channel manometer. The wing model was designed in such a way that there were three static pressure holes on each three different span wise stations sharing a single tube. Hence, during the experiment the pressure was taken on a station by station basis and the remaining 2 pressure holes were closed using a thin tape. To avoid a higher flow separation between the model and wall at higher angle of attack, the test with the store installed was carried out at zero angle of attack only.

\section{Computational fluid dynamic simulation}

In the CFD simulation, the mid wing was simulated under two different conditions. In the first condition, the mid wing was meshed into 111239 elements, while in and the second condition it was meshed into 221112 elements, as shown in Fig. $6 \mathrm{a}$ and $6 \mathrm{~b}$. The flow was simulated at speed $22 \mathrm{~m} / \mathrm{s}$, incompressible flow and was considered laminar. Fig. 6c shows the simulation for a wing with external storage with 122158 elements. Fig. 7 below shows the simulation results for the mid wing that was generated with two

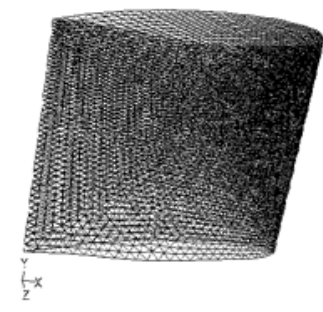

(a) Mesh for wing in tunnel 111,239 elements

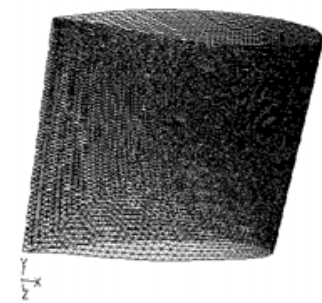

(b) Mesh for wing in tunnel, 221,112 elements

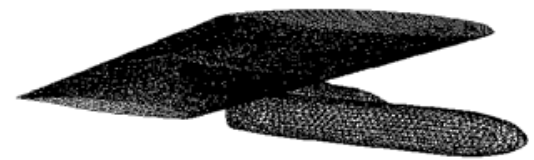

$$
x^{x} x
$$

(c) Mesh for wing and store in tunnel, 122,158 elements

Fig. 6: CFD model surface meshes 
different elements. This implies that the simulation at around 120000 elements was acceptable.

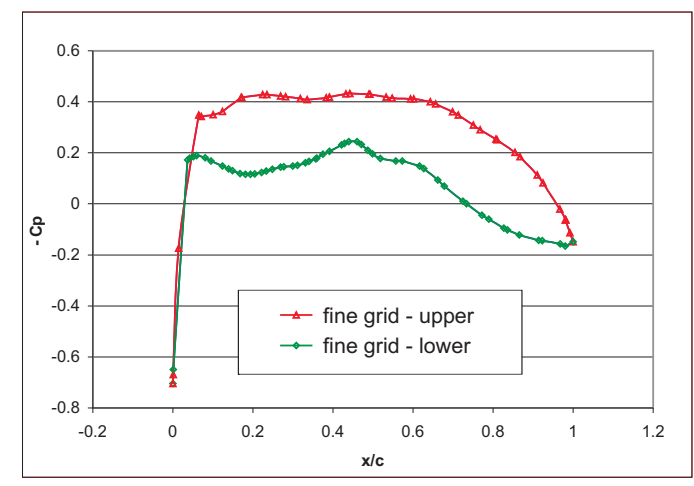

Fig. 7: Pressure distributions at the mid span for upper and lower surface

\section{Results}

\section{Wind tunnel testing results}

After a series of experiments had been conducted, the pressure distribution at mid span for the upper and lower surfaces was plotted, as shown in Fig. 8.

From these results it was found that at station 1 the difference in pressure coefficient is only $3 \%$ on the upper surface of the wing compared to the lower surface, due to the external store installations. There are substantial differences in pressure coefficient on the lower surface with the external store configuration. Station 2 and 3 indicate the same phenomenon and that there is a small difference in pressure distribution on the upper surface. The lower surface shows some reduction in pressure distribution. These experimental results give an initial indication that the flow on the upper surface will not be severely affected by the external storage configuration compared to the lower surface.

\section{Computational fluid dynamics results}

Fig. 9 shows the results of CFD simulation on the upper and lower surfaces of the wing of this aircraft. At station 3, it is shown that the pressure coefficient is almost constant and unchanged from the leading edge to trailing edge on the upper surface, and the value does not change very much with the external store installation. This shows that the external store did not affect the flow on the upper surface. In contrast the pressure coefficient shows a significant change on the lower surface with the external store compared to the clean wing configuration. This result showed that the external storage only affected the lower surface. The same phenomenon also occurs at station 1 where the coefficient of pressure has not changed at the upper surface but there is some reduction in the pressure coefficient distribution on the lower surface compared to the upper surface. The results at station 2 are the same.

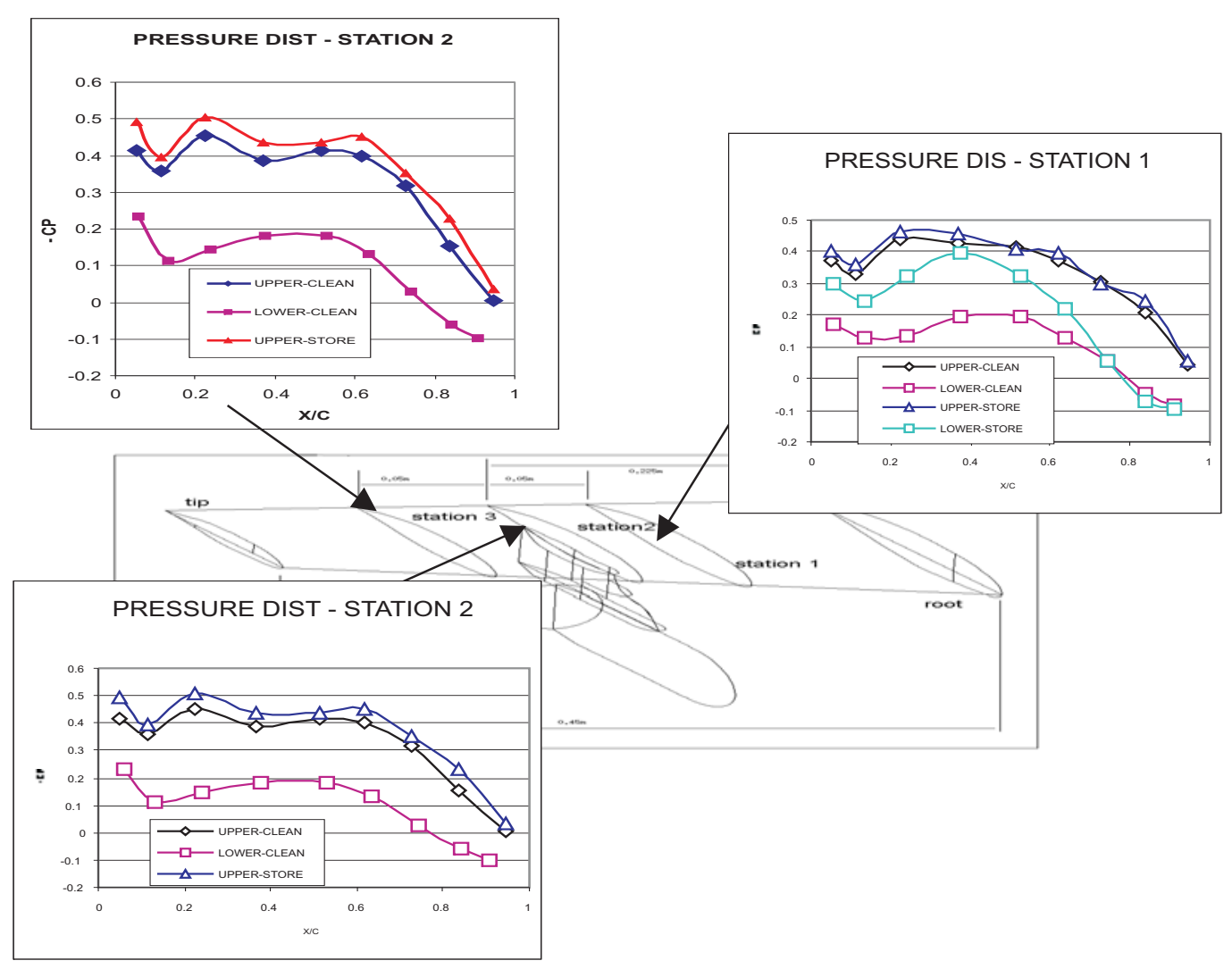

Fig. 8: Pressure distribution for a various chord wise location surrounding the store (experiment) 


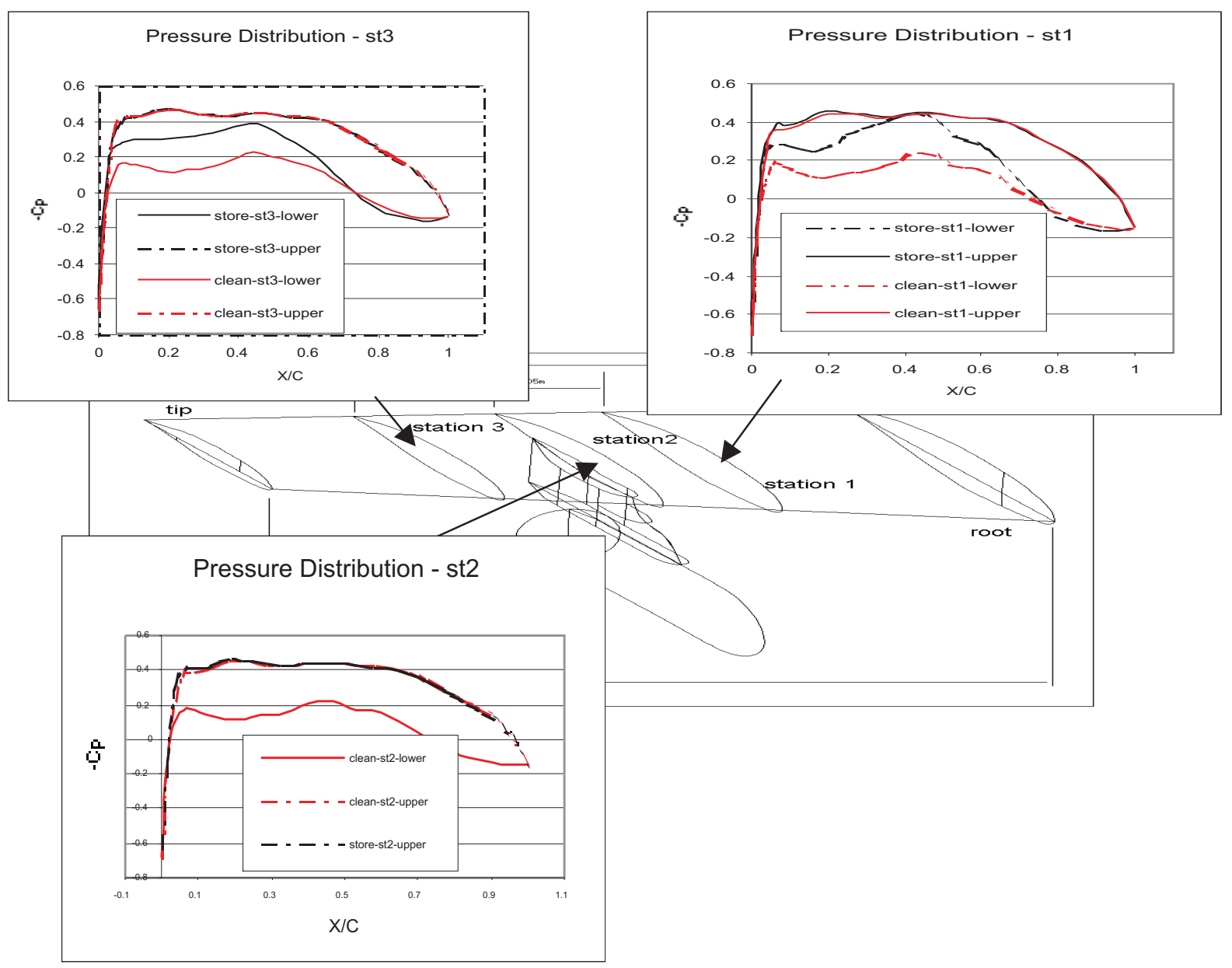

Fig. 9: Pressure coefficient at three different span wise locations (CFD)

\section{Analysis and discussion}

\section{Comparison between CFD and experimental works}

The study shows that the value of the pressure coefficient predicted by simulation compared well to that performed in the experimental study. There is an average difference of about $19 \%$ between the two values. In the experimental study, a problem during the setup of the experiment such as misalignment in determining the angle of attack, accuracy of the model, blockage effects and wind tunnel calibration can significantly influence the result. Though the wing was machined accurately by the computer numerical control (CNC), there was still some doubt about the accuracy of the model. Moreover, the fluid level of the manometer used for measuring the pressure fluctuated constantly between 2 to $3 \mathrm{~mm}$.

\section{Discussion}

In the study we observed that the external store configuration only affects the lower surface of the wing. Fig. 10 shows the pressure distribution at the quarter chord point along the span wise location from the tip to the root. On the upper surface, the pressure distribution is almost constant in the span wise direction, which is from the tip to the root of the wing. The pressure coefficient on the lower surface was reduced by $40 \%$ compared to the upper surface. With the external store installed, the pressure distribution on the lower surface was increased to around $20 \%$ compared to the clean wing configuration. There was a sudden increase in pressure distribution at the position of 0.2 span wise location, where the external storage was mounted to the wing. Fig. 11 shows the results of the simulated aerodynamic force coefficient at zero angle of attack, Reynolds number of $1.86 \times 10^{5}$ and Mach number 0.067. This figure shows the simulated value of the lift coefficient and drag coefficient for the wing alone and the wing with the store configuration. It should be noted here that the external storage decreased the total coefficient of

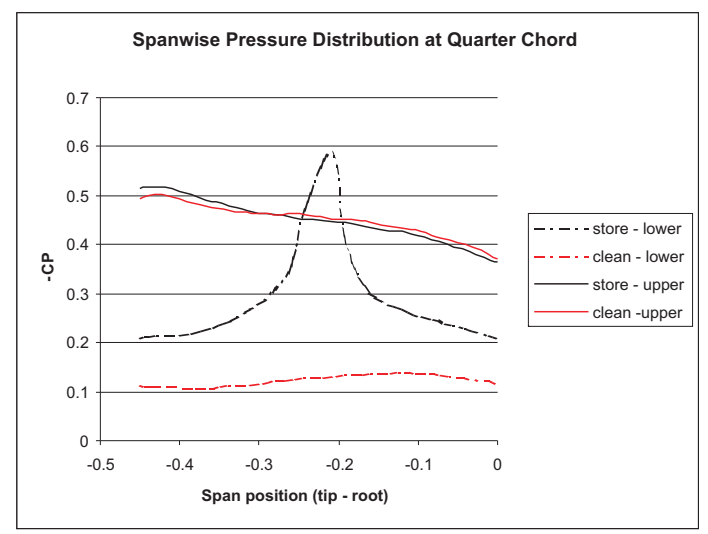

Fig. 10: External store interference on pressure distribution 


\begin{tabular}{|c|c|c|c|c|c|c|}
\hline \multirow{2}{*}{} & \multicolumn{3}{|c|}{ Wing } & \multicolumn{3}{c|}{ Wing-Store } \\
\cline { 2 - 7 } & Pressure & Viscous & Total & Pressure & Viscous & Total \\
\hline Lift Coeff. & 0.2528 & Negligible & 0.2528 & 0.1767 & Negligible & 0.1767 \\
\hline Drag Coeff. & 0.0128 & 0.0018 & 0.0146 & 0.0295 & 0.0024 & 0.0318 \\
\hline
\end{tabular}

Fig. 11: Simulated aerodynamic forces, $\alpha=0, \operatorname{Re}=1.86 \times 10^{5}, M=0.067$

lift from 0.2528 to 0.1767 and increased the coefficient of drag from 0.0146 to 0.0318 . This shows that the store installation significantly influenced the drag coefficient compared to the lift coefficient.

In this initial stage of research, the wind tunnel test was carried out at a speed of $22.8 \mathrm{~m} / \mathrm{s}$ corresponding to a Reynolds number of $1.86 \times 10^{5}$, which was low for a fighter aircraft. However, the test was meant to validate the CFD simulation, which was performed on the wing and store configuration at the same Reynolds number. In order to perform an experimental and simulation study as close as possible to the real situations the Reynolds number similarity has to be increased to an order of several million. This will be performed in the next phase of the study in a bigger wind tunnel facility with a working section of $2 \mathrm{~m} \times 1.5 \mathrm{~m}$.

\section{Conclusion}

In conclusion, the main objective in this project was achieved. It has been shown that CFD simulation is an important tool for investigating the influence of store interference characteristics for a subsonic fighter aircraft. The static pressure measured around the wing was about $19 \%$ higher than the simulated values. The results show that the flow over the upper surface of the wing was not much affected when the pylon and launcher were installed. The study also shows that the flow over the lower surface was much more affected by the presence of the external store. The methods for determining the influence of stores on the wing will be used to simulate the full size of this fighter aircraft with real size external store. The ongoing project is to compare the full CFD model of this fighter aircraft with the wind tunnel model that was tested in a bigger wind tunnel facility of working section $2 \mathrm{~m} \times 1.5 \mathrm{~m}$ at Universiti Teknologi Malaysia.

\section{References}

[1] Bhardwaj, M. K., Kapania, R. K., Reichenbach, E., Guruswamy, G. P.: Computational Fluid Dynamics/Computational Structural Dynamics Interaction Methodology For Aircraft Wings. AIAA Journal, Vol. 36, No. 12, 1998, p. 2179-2185.

[2] Tomaro, R. F., Witzeman, F. C., Strang W. Z.: Simulation Of Store Separation For The F/A-18c Using Cobalt. Journal of Aircraft, Vol. 37, No. 3, 2000, p. 361-367.
[3] Prewitt, N. C., Belk, D. M., Maple, R. C.: Multiple-Body Trajectory Calculations Using the Beggar Code. Journal of Aircraft, Vol. 36, No. 5, 1999, p. 802-808.

[4] Brock, J. M. Jr, Jolly B. A.: Application of Computational Fluid Dynamics at Elgin Air Force Base. SAE 985500, 1988.

[5] Shanker, V., Malmuth, N.: Computational And Simplified Analytical Treatment of Transonic Wing/Fuselage/Pylon/Store Interaction. Journal of Aircraft, Vol. 18, No. 8, 1981, p. 631-637.

[6] Hirsch: Numerical Computation of Internal and External Flows. Volume 1. Brussels: Wiley, 1988.

[7] Jameson, A.: Re-Engineering the Design Process through Computation. Journal of Aircraft, Vol. 36, No. 1, 1999.

[8] Spradley, L. W., Lohner, R., Chung, T. J.: Generalized Meshing Environment for Computational Mechanics. AIAA Journal, Vol. 36, No. 9, 1996, p. 1735-1737.

[9] Mavriplis, D. J.: Viscous Flow Analysis Using A Parallel Unstructured Multigrid Solver. AIAA Journal, Vol. 38, No. 11, 2000, p. 2067-2075.

[10] Kallinderis, Y., Khawaja, A., Mcmorris, H.: Hybrid Prismatic/Tetrahedral Grid Generation for Viscous Flows around Complex Geometries. AIAA Journal, Vol. 34, No. 2, 1996, p. 291-298.

[11] Koomullil, R. P., Soni, B. K.: Flow Simulation Using Generalized Static and Dynamic Grids. AIAA Journal, Vol. 37, No. 12, 1999, p. 1551-1557.

Tholudin Mat Lazim, Ph.D.

e-mail: tholudin@fkm.utm.my

Shabudin Mat, M.Sc

e-mail: shabudin@fkm.utm.my

Department Aeronautics \& Automotive

Faculty Mechanical Engineering

Universiti Teknologi Malaysia

81310, UTM Skudai, Johor Malaysia

Huong Yu Saint, M.Eng

Royal Malaysian Airforce

Wisma Pertahanan

Jalan Padang Tembak

50634, Kuala Lumpur, Malaysia 